\title{
Conformidade ergonômica dos controles no posto de trabalho do operador de trator: Estudo de Caso Nh 7630
}

\author{
Compliance ergonomic controls at the workplace of the operator of tractor: Case Study NH \\ 7630
}

\author{
ROSSI, Marcos Antonio, Doutor; Universidade Estadual Paulista - UNESP/Bauru \\ mrossi@faac.unesp.edu.br
}
SANTOS, João Eduardo Guarnetti dos, Doutor; Universidade Estadual Paulista - UNESP/Bauru
guarneti@feb.unesp.edu.br

\begin{abstract}
SILVA, André Luis da; Doutor; Universidade Tecnológica Federal do Paraná - UTFPR/Medianeira andrels@utfpr.edu.br
\end{abstract}

\begin{abstract}
Resumo
Este artigo aborda uma análise ergonômica dos controles utilizados pelos operadores de tratores, abordando seus posicionamentos em relação ao invólucro do seu posto de trabalho. Foi executada uma avaliação dos controles do posto de trabalho de um trator modelo NH 7630 de potência média de $74 \mathrm{~kW}$ (100 CV), utilizando-se das normas vigentes da ABNT. Com esta triagem foi possível detectar os pontos positivos e negativos. Em seguida, efetivou-se um estudo analítico dos controles. Os resultados desta avaliação demonstram, que alguns controles dos tratores avaliados possuem erros em relação à NBR/ ISO 6682.
\end{abstract}

Palavras-Chave: Ergonomia; Posto de trabalho; Tratores agrícolas.

\begin{abstract}
This article discusses an ergonomic analysis of the controls used by tractor operators, covering their positions in relation to the casing of your job. Was performed an assessment of the controls of the job of a model NH 7630 tractor average power of $74 \mathrm{~kW}(100 \mathrm{CV})$, using the norms of the ABNT. With this screening could detect the positive and negative. Then was accomplished an analytical study of the controls. Evaluation results show that some controls of tractors have errors evaluated in relation to NBR/ ISO 6682 .
\end{abstract}

Keywords: Ergonomic; Workstation; Tractors.

\section{Introdução}

A atividade do operador de trator quase sempre é muito fatigante, com jornadas de trabalho extensas e sujeita as condições climatológicas que afeta a operacionalidade do equipamento e seu rendimento produtivo. Para amenizar as conseqüências prejudiciais a sua atividade, o posto de trabalho do operador de trator deve ter condições mínimas necessárias para que seu trabalho seja executado de tal forma que não ocorra riscos a sua saúde e de acidentes.

Apesar de conduzir o veículo e de verificar o implemento acoplado, podemos considerar que a atividade do tratorista e monótona, com pouco estímulo. Após a regulagem da velocidade

Projética Revista Científica de Design I Universidade Estadual de Londrina I V.2 I N.1 I Junho 2011 
Marcos Antonio Rossi; João Eduardo Guarnetti dos Santos; André Luis da Silva

do trator, o tratorista possui em grande parte de sua atividade o ato de direcionar o veiculo utilizando um controle o volante, e atentar não somente para o que ocorre à sua frente, como necessita de uma visualização constante do implemento que está sendo rebocado atrás do trator, sendo que em alguns casos pode ter de acionar algum comando no processo. Esta interface que o operador tem com o trator se dá por meio de controles, mostradores ou sinais sonoros, justificando, portanto, a importância da aplicação da ergonomia no desenvolvimento de um produto.

A ergonomia tende a harmonizar o processo da execução de uma determinada tarefa, conciliando a máquina com o homem, utilizando aspectos como a antropometria, psicologia, ambiente, biomecânica e a fisiologia humana, respeitando as características do homem para seu beneficio.

\section{Ergonomia}

De acordo com Pheasant (1997 apud MORAES; MONT' ALVÃO, 2000), a "Ergonomia é a ciência que objetiva adaptar o trabalho ao trabalhador e o produto ao usuário".

Segundo Vidal (2004), a prática da ergonomia visa alterar o sistema de trabalho ajustando a atividade existente às características, habilidades e restrições do homem em relação à execução, desempenho eficaz, cômodo e livre de perigo.

Para Dul e Weerdmeester (2004), a ergonomia tornou-se mais forte durante a Segunda Guerra Mundial, quando se iniciou a mobilização harmonizadora de várias tecnologias e ciências humanas, como a Fisiologia, Psicologia, Antropologia, Medicina e o esforço de engenheiros em prol do desenvolvimento bélico. A indústria aproveitou essa nova fusão de conhecimentos e de informações aplicando-os em sua linha de produção, que na seqüência trouxe conforto para a vida cotidiana.

Estando consolidada a ergonomia na indústria, nasce na Europa, em 1947, a Ergonomics Research Society e, dessa consolidação, surge a Human Factors Engineering ou HFE, que segue a prática da Ergonomia em uso civil, segundo relato de Vidal (2004).

Com a utilização da ergonomia na atividade civil, lida (2005) comenta que essa nova ciência deve ter como objetivo, aspectos do comportamento humano e outros fatores como, por exemplo:

-homem: características físicas, fisiológicas, psicológicas e sociais do trabalhador, influência de sexo, idade, treinamento e motivação.

-máquina: todas as ajudas materiais que o homem utiliza no seu trabalho, englobando equipamentos, ferramentas, mobiliário e instalações.

-ambiente: as características físicas que envolvem o homem durante o trabalho, como temperatura, ruídos, vibrações, luz, cores, gases e outros.

-informação: as comunicações existentes entre os elementos de um sistema, a transmissão de informações, o processamento e a tomada de decisões.

-organização: a conjunção dos elementos acima citados no sistema produtivo, incluindose aspectos como horários, turnos de trabalho e formação de equipes.

-conseqüências do trabalho: as questões de controle como tarefas de inspeções, estudos dos erros e acidentes, além dos estudos sobre gastos energéticos, fadiga e "strees".

Em conseqüência da evolução tecnológica, as máquinas se tornaram mais rápidas, precisas, confiáveis e "inteligentes" e, por isso, os operadores precisam ter maior conhecimento

Projética Revista Científica de Design I Universidade Estadual de Londrina I V.2 I N.1 I Junho 2011 
Conformidade ergonômica dos controles no posto de trabalho ... : Estudo de Caso Nh 7630 sobre os novos equipamentos, sobre seu trabalho e sobre o processo que está envolvido neste contexto (IIDA, 2005).

\section{Posto de Trabalho}

Para Laville (1977), o posto de trabalho faz parte da composição do sistema. A tarefa de um operador depende de tarefas realizadas por outros operadores; quando é necessário o trabalho em equipe exige que um operador execute outras tarefas em outros postos de trabalho. O mesmo autor afirma da contribuição da ergonomia, a qual tem como abrangência, o método da análise de um sistema.

A definição de sistema - homem - máquina, segundo Grandjean (1998), é "a relação de reciprocidade entre a máquina e o ser humano que a opera". De acordo com Dul e Weerdmeester (2004), é a partir da comunicação entre estes elementos que se dá o processo de decisão, o qual tem-se tornado cada vez mais rápido.

Para Grandjean (1998), o sistema insere o homem em um ciclo fechado entre o homem e a máquina, se cujas etapas são: perceber a indicação do mostrador na máquina, interpretar os dados, refletir para a tomada de decisão, executar uma tarefa de manuseio do controle, verificar no indicador do controle se a alteração feita está correta, observar a produção e visualizar o resultado no mostrador da máquina.

É possível ver o posto de trabalho sob dois enfoques, segundo lida (2005): o tradicional e o ergonômico. O tradicional mantém os fundamentos da economia dos movimentos, a qual é uma visão Taylorista, já o enfoque ergonômico tende a desenvolver o posto de trabalho para reduzir as exigências biomecânicas, visando o conforto e um menor esforço físico do operador. Para isso deve-se projetar ou alterar um posto de trabalho adequado para as necessidades humanas.

Para Montedo (2001), o agricultor fica á mercê de projetos mal elaborados sem que possa fazer valer a sua opinião, não obstante seja ele o indivíduo que tem o maior interesse e conhece a realidade de seu trabalho.

Estudos feitos por Pheasant e Harris (1982) analisaram o difícil trabalho do tratorista, que está sujeito a vários fatores como ruído, vibração, poeira, calor, intempéries e monotonia. No início, o homem utilizava o arado de tração animal, tendo a sua visão direcionada para a frente, no mesmo sentido da tarefa, conforme a Figura 1.
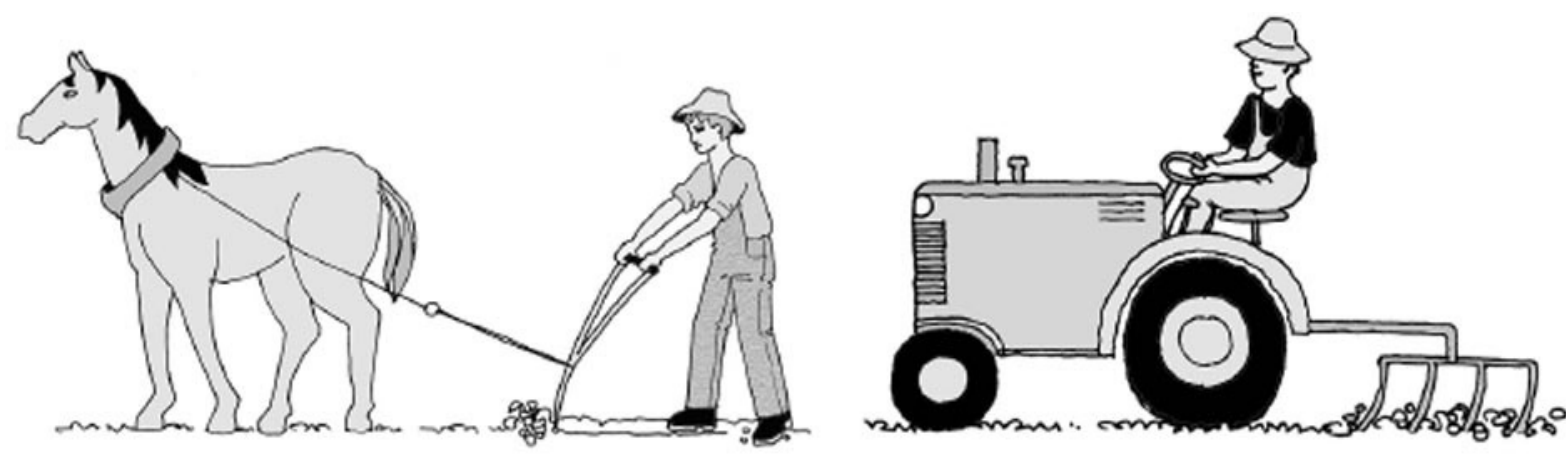

Figura 1 - Substituição do arado de tração animal, pelo trator. Fonte: lida (2005). 
Marcos Antonio Rossi; João Eduardo Guarnetti dos Santos; André Luis da Silva

Segundo Gomes, Santos e Fernandes (2005), há uma grande falha em projetos agrícolas no que diz respeito a indicações ergonômicas individuais e as de ambiente de trabalho, que pode ocasionar acidentes ao trabalhador rural.

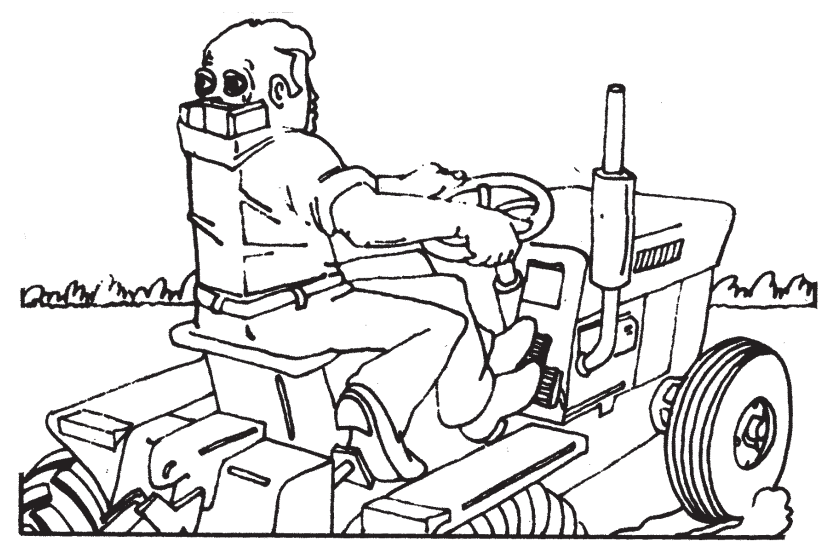

Figura 2 - Tratorista ideal

Fonte: Pheasant e Harris (1982).

Para Pheasant e Harris (1982) o tratorista ideal, representado na Figura 2, deveria ter três pernas, dois olhos atrás da cabeça e uma coluna de ferro, apesar da evolução tecnológica, algumas destas recomendações para o agricultor ainda deve ser utilizada para alguns comandos.

\section{Controles}

A manipulação da máquina dá-se pelo princípio do movimento do controle, que é a transferência de uma força humana, para que a máquina possa executar alguma operação. Esse movimento pode ser através das mãos, pés ou da fala, como exemplo tem-se um simples apertar de botão com o dedo, ou o ato de fazer uma ligação do celular falando apenas o nome da pessoa (IIDA, 2005).

A concordância dos movimentos da máquina para com o homem deve seguir o movimento natural do corpo, segundo Murrell (1965).

O estereótipo popular é o movimento provável, ou seja, o movimento assimilado pela maioria da população, como se observa no ato de ligar ou aumentar. Relaciona-se ao sentido horário. Os que seguem o estereótipo popular são chamados de compatíveis, e os que não seguem, são chamados de incompatíveis (IIDA, 2005).

Conforme o mesmo autor, a compatibilidade espacial dá-se no sentido do movimento indicado pelo controle e pelo mostrador e vice-versa. Com o deslocamento de uma alavanca para a direita, por exemplo, o mostrador tenderia a se movimentar para a mesma direção.

Para a movimentação dos controles, deve-se considerar também a sensibilidade do deslocamento. Os controles de baixa sensibilidade têm um maior tempo de deslocamento e são mais fáceis de serem ajustados, são os chamados discretos, ao contrário dos controles de alta sensibilidade, chamados de contínuos, os quais movimentam mais rapidamente, mas são mais difíceis para ajustar.

Segundo Grandjean (1998), a escolha de um determinado controle dá-se pela sua função e pela sua necessidade de precisão, cada controle tem suas características para uma determinada utilidade. Para o uso correto dos comandos, objetivando-se evitar acidentes, devem-se levar em consideração, os seguintes aspectos apontados pelo autor, como a

Projética Revista Científica de Design I Universidade Estadual de Londrina I V.2 I N.1 I Junho 2011 
Conformidade ergonômica dos controles no posto de trabalho ... : Estudo de Caso Nh 7630 codificação, distância, resistência e cor, sua localização para os controles manuais, na qual devem ser facilmente alcançado em uma altura entre o cotovelo e os ombros.

Segundo Schlosser et al. (2002), os acidentes com tratores agrícolas merecem atenção, pois representam porcentagem significativa. Na Europa, conforme Márquez (1986), cerca de $40 \%$ do total de acidentes ocorridos no setor agrário abrange máquinas agrícolas, sendo $50 \%$ provenientes do uso do trator agrícola.

A aplicação da ergonomia para o trabalho do homem é primordial para estabelecer o conforto e a segurança do operador, como foi visto anteriormente. Portanto, o uso e o dimensionamento errado dos controles, comandos e manejos num longo espaço de tempo, pode provocar lesões, diminuição da produtividade e irritabilidade do operador. Sendo assim, todas estas informações serão aplicadas no novo leiaute do posto de trabalho do tratorista, fazendo com que o posto de trabalho se torne totalmente uma extensão de seu corpo (DUL; WEERDMEESTER, 2004).

\section{Antropometria}

Para Santos et al. (1997), o objetivo da antropometria é levantar dados dimensionais de diferentes partes do corpo. Panero e Zelnik (2002) salientam a importância da antropometria em estabelecer diferenças individuais de cada indivíduo e não considerando a antropometria como um simples ato de medições do corpo humano, mas, sim, como uma análise mais detalhada de dados utilizados pela ergonomia ou outras áreas.

lida (2005) divide em dois os métodos antropométricos, os diretos e indiretos. Segundo ele, os métodos diretos são aqueles que mantêm o contato físico com o organismo, para isso são utilizados equipamentos para medições lineares, angulares, de superfície tridimensional, de peso e forças, esses equipamentos são: régua, trenas, fitas métricas, esquadros, paquímetros, transferidores, balanças, dinamômetros e outros necessários.

Para medições diretas, Dempsey (1963 apud IIDA, 2005) desenvolveu um dispositivo para medições de alcance dos membros superiores, utilizando réguas escalonadas, conforme a Figura 3.
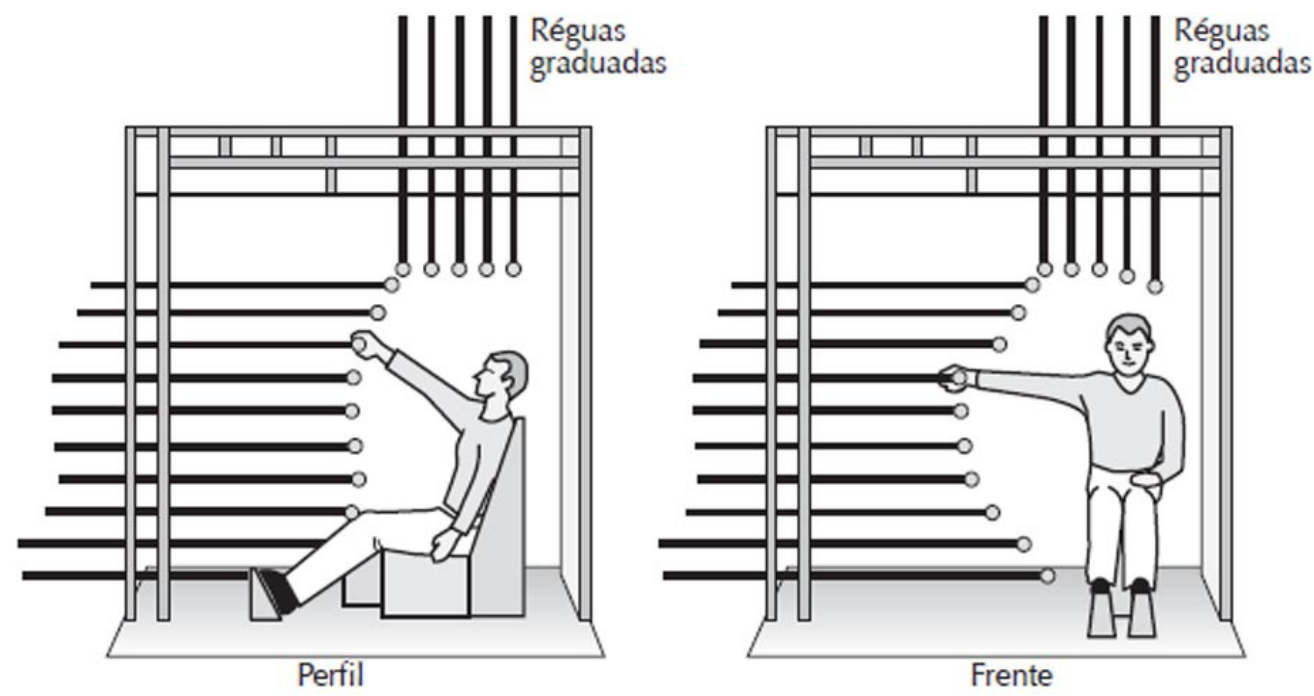

Figura 3 - Dispositivo para medir alcance dos membros superiores na posição sentada.

Fonte: Dempsey (1963 apud IIDA, 2005). 
Marcos Antonio Rossi; João Eduardo Guarnetti dos Santos; André Luis da Silva

lida (2005) ressalta a importância do posicionamento do corpo humano em relação ao seu posto de trabalho, seus alcances e movimentos. Os movimentos que tendem a se afastar da posição normal do corpo, é chamado de abdução, tem-se como exemplo o movimento do membro inferior, para o acionamento de uma alavanca de pé, caso esse controle esteja posicionado em um local incorreto, pode ocasionar uma lesão para o operador em uso freqüente deste controle.

Conforme Russo, Ilgner e Buzatto (1998), os equipamentos e implementos agrícolas não são projetados com dados antropométricos do agricultor brasileiro e não têm o seu dimensionamento correto para determinados acionamentos. Sendo projetadas em outros países, estas máquinas possuem dados de regiões com perfil alterado, até mesmo dentro do território brasileiro. Por serem diferentes as colonizações étnicas podem-se alterar essas dimensões.

Para Gomes, Santos e Fernandes (2005) existem variáveis incontáveis relacionadas à produção agrícola, na qual não se pode determinar um modelo característico do usuário. Entre essas variáveis estão à diversidade antropométrica, os biótipos da população, a alta rotatividade das tarefas.

\section{Materiais e Métodos}

\section{Materiais}

Para a avaliação dos controles do posto de trabalho do tratorista, foi utilizado um trator com de potência de $(73.550 \mathrm{~W})$. As características do trator utilizado para a pesquisa estão apresentadas na Tabela 1. A coleta de dados foi realizada com um trator novo, cedido gentilmente pela concessionária autorizada da marca, localizada na cidade de Londrina Paraná. O trator utilizado para a pesquisa apresenta posicionado em um piso de cimento nivelado e com cobertura para não alterar as condições de coleta de dados.

Tabela 1 - Características do trator John Deere 6405.

\begin{tabular}{cc} 
Descrição & Características* \\
\hline Marca & New Holland \\
Fabricante & CNH Latino \\
Modelo & 7630 \\
Potência bruta & $76 \mathrm{~kW}$ a $2.200 \mathrm{rpm}$ \\
Número de cilindros & $106 \mathrm{cv}$ a $2.200 \mathrm{rpm}$ \\
Cilindradas $\mathrm{cm}^{3}$ & Quatro cilindros \\
Aspiração & 4500 \\
Tração & Turbo \\
Peso & $4 \times 4$ \\
Newton (N) & $35.598 \mathrm{~N}$ \\
Quilograma (kg) & $3630 \mathrm{~kg}$ \\
Cabina & (peso de embarque) \\
\hline
\end{tabular}

*Informações obtidas no manual do fabricante. 
Conformidade ergonômica dos controles no posto de trabalho ... : Estudo de Caso Nh 7630

Para esta avaliação foi utilizada a ergonomia do arranjo físico, citada por Santos et al. (1997), a qual analisa o leiaute para um melhor posicionamento dos comandos, tendo como referência as normas vigentes da ABNT, relacionando à área de alcance dos membros superiores e inferiores.

Para as medições, foram utilizados os seguintes materiais:

- três réguas de balcão com comprimento de $1000 \mathrm{~mm}$;

- uma trena de aço aferida;

- um nível tradicional;

- um nível circular bolha para alinhamento das réguas;

- um paquímetro;

- um prumo;

- quatro linhas guias.

\section{Métodos}

A metodologia utilizada para as medições tem como fundamento NBR/NM/ISO 5353 (1999) - Máquinas rodoviárias e tratores e máquinas agrícolas e florestais - Ponto de Referência do Assento ou SIP, mas para a sua utilização é necessário o conhecimentos de outra norma a NBR/ISO 4130 (2007) - Veículos rodoviários automotores - Sistema de referência tridimensional e marcas de referência - Definições, para a definição dos três planos ortogonais do veículo.

Em seguida, foi feito o dispositivo referente à norma NBR/NM/ISO 5353 (1999) - Máquinas rodoviárias e tratores e máquinas agrícolas e florestais - Ponto de Referência do Assento ou SIP, é o ponto inicial que estabelece dimensões para o assento do operador e a localização dos controles dispostos no posto de trabalho. Para o projeto do dispositivo, considerou-se todos os requisitos técnicos para o seu desenvolvimento, sendo verificadas todas as medidas recomendadas. No processo de fabricação foi utilizada madeira polida com lixa de grana 200.

Em relação ao peso do dispositivo, a norma exige que a massa deve estar entre $6 \mathrm{~kg} \pm$ $1 \mathrm{~kg}$. $O$ projeto foi refeito tridimensionalmente na plataforma CAD para uma melhor análise das variáveis citadas pela norma, como espaço interno para a inserção de massa e o centro da força da vertical, conforme demonstrado na Figura 4.

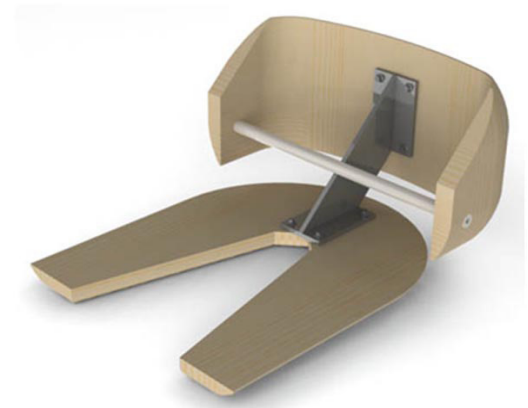

Figura 4 - Imagem ilustrativa digital do dispositivo para determinação do ponto SIP.

Fonte: Autoria própria.

A norma NBR/NM/ISO 5353 determina que para a realização das medições, deve-se adicionar uma massa de $66 \mathrm{~kg} \pm 1 \mathrm{~kg}$, para isso foram confeccionados quatro blocos de chumbo de $13,9 \mathrm{~kg}$ cada. Os blocos foram desenvolvidos de maneira que o dispositivo se posicionasse o mais próximo possível do seu centro de força vertical. 

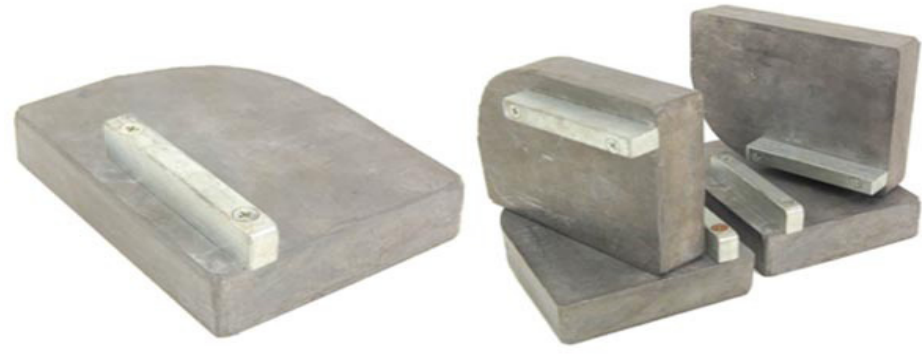

Figura 5 - Blocos de chumbo.

Fonte: Autoria própria.

Após adotados o dispositivo e os pesos em chumbo, segue-se para o procedimento padrão da norma, em que se deve manter a regulagem do assento em posição mediana, conforme mostra a Figura 6, com o travamento da suspensão do mesmo.

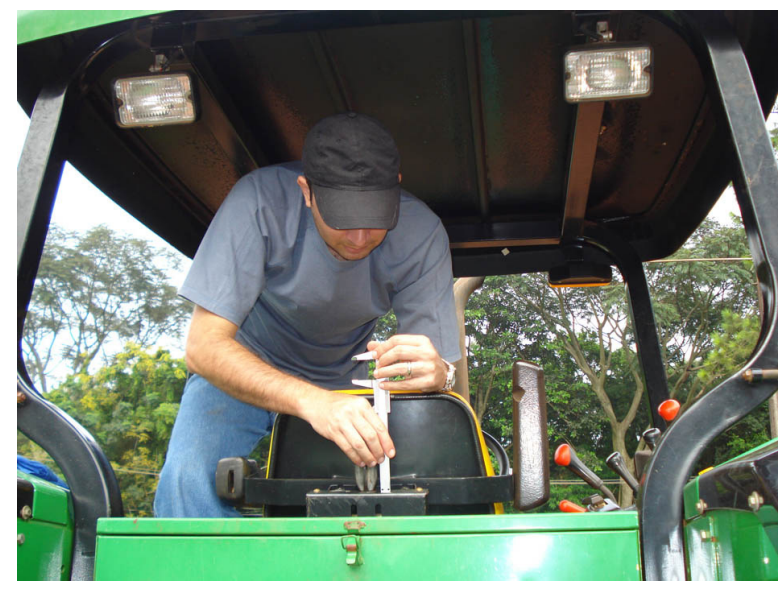

Figura 6 - Regulagem do assento.

Fonte: Autoria própria.

Após o ajuste do assento, foi posicionada uma pessoa com peso entre $75 \mathrm{~kg} \pm 10 \mathrm{~kg}$, duas vezes em intervalos de 1 minuto, conforme mostra a Figura 7.

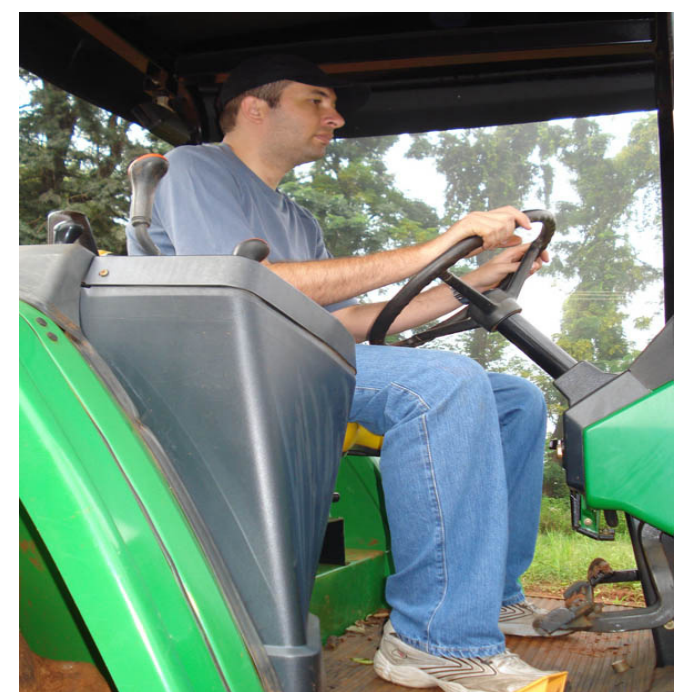

Figura 7 - Operador sentado flexionando o assento e o encosto.

Fonte: Autoria própria.

Projética Revista Científica de Design I Universidade Estadual de Londrina I V.2 I N.1 I Junho 2011 
Conformidade ergonômica dos controles no posto de trabalho ... : Estudo de Caso Nh 7630

Depois deste procedimento houve um intervalo de 5 minutos, conforme recomenda a norma, e foi colocado ao assento e ao encosto um tecido de musselina para evitar o contato direto e minimizar a fricção, conforme mostra a Figura 8.

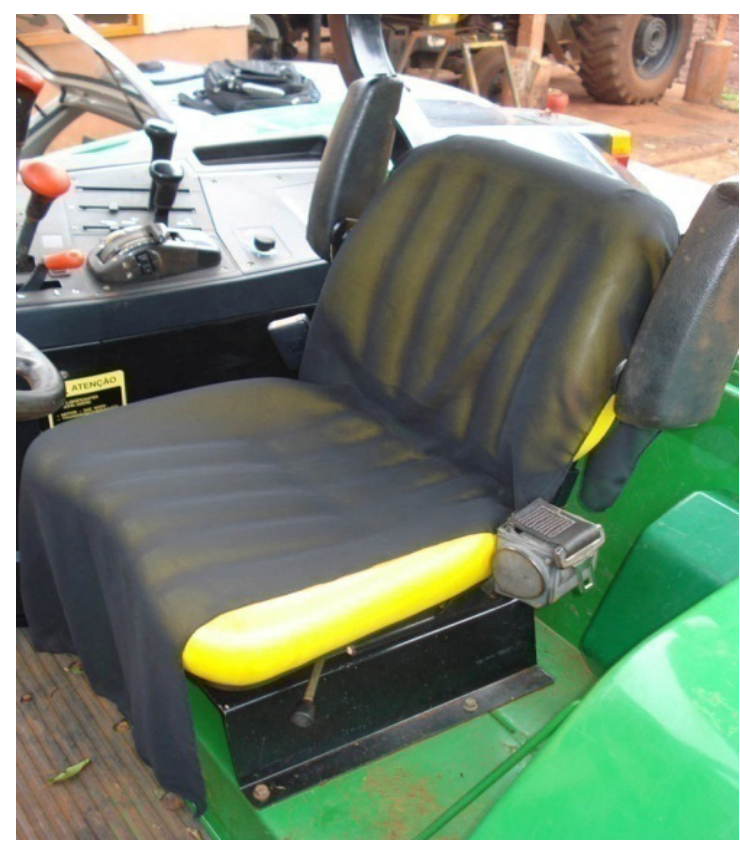

Figura 8 - Tecido de musselina no encosto e no assento.

Fonte: Autoria própria.

Na seqüência, foi adicionado um peso de chumbo para alterar a massa de $6 \mathrm{~kg}$ para 26 $\mathrm{kg}$, e também foi empurrado o dispositivo contra o encosto e se balança de lado a lado. Este procedimento exigido pela norma é mostrado na Figura 9.

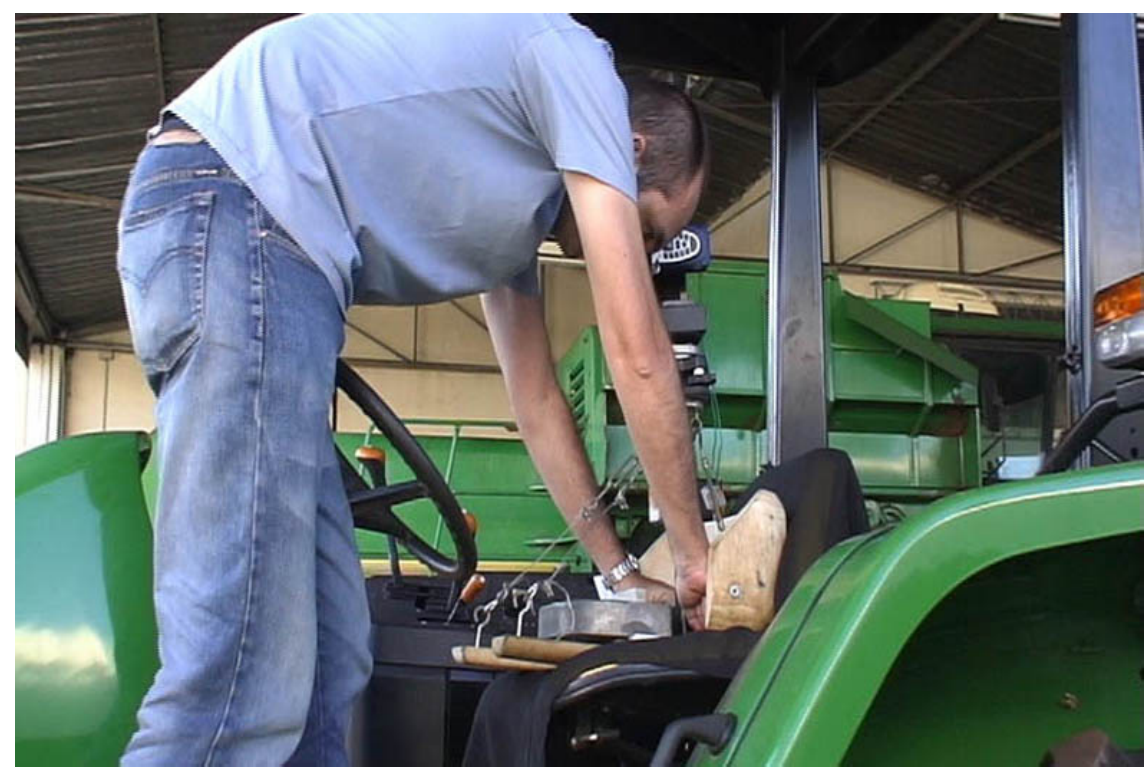

Figura 9 - Movimentação sobre o dispositivo.

Fonte: Autoria própria.

Em seguida foram adicionados ao dispositivo, pesos de chumbo para alcançar a massa de $65 \mathrm{~kg}$ recomendada pela norma, como mostra a Figura 10.

Projética Revista Científica de Design I Universidade Estadual de Londrina I V.2 I N.1 I Junho 2011 


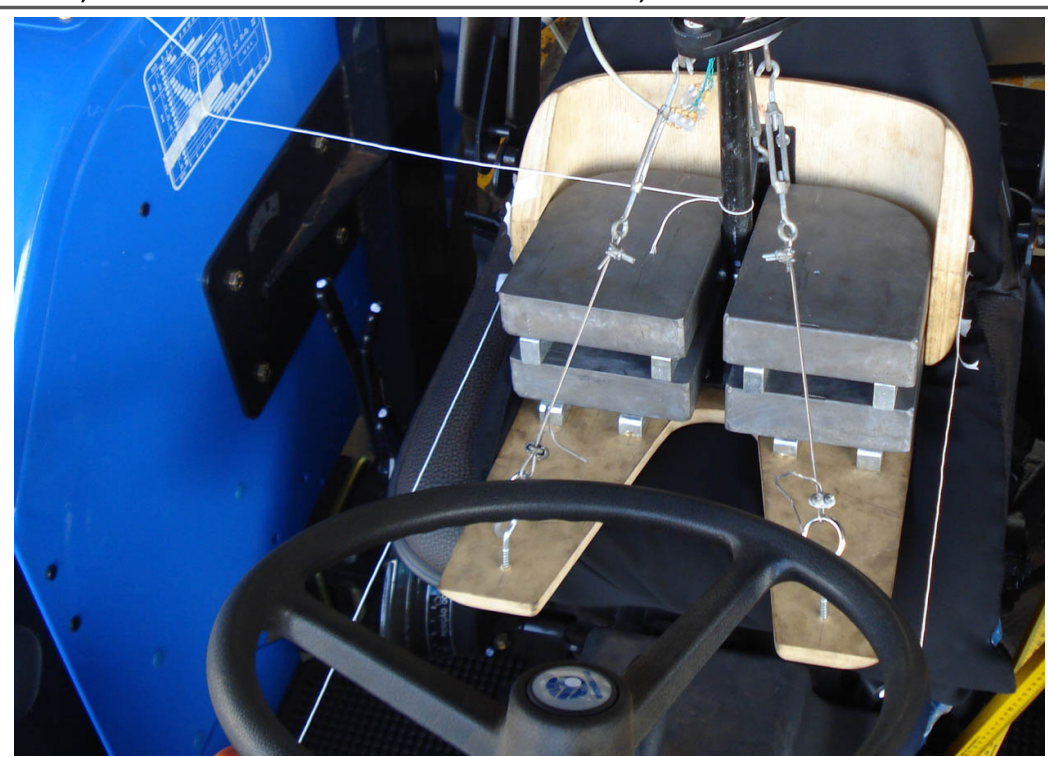

Figura 10 - Dispositivo com pesos e linhas guias. Fonte: Autoria própria.

Após ser inserido o dispositivo, pôde-se iniciar o processo de medição. Para tanto, foi feita uma adaptação da metodologia utilizada por Rozin (2004), em que se usou uma linha de guia para os eixos $\mathrm{X}$ e $\mathrm{Y}$. Neste processo foram utilizadas para as medições no processo manual tradicional duas linhas guias no sentido do eixo $Y$, pois, conforme a norma deve ser utilizada estes pontos de medição para cada lado do dispositivo. Demonstrado na Figura 10.

\section{Resultados e Discussões}

Os resultados apresentados foram inseridos em tabelas e gráficos, para as análises comparativas. Após a coleta dos dados foram confrontados com a norma NBR ISO 6682 (2004) Máquinas rodoviárias - Zonas de conforto e alcance dos controles, para verificar a conformidade dos controles. Está norma tem como objetivo a delimitação das zonas de conforto e alcance ao compartimento do operador sentado de máquinas rodoviárias.

A norma define a separação dos controles em principais, relativo ao trator como direção, transmissão (câmbio e grupos), freios (pedais direito e esquerdo), rotação do motor (acelerador manual e acelerador de pé) e embreagem. E os controles secundários, de uso não freqüente, como tração, tomada de força, controle remoto, redução de marcha, controle do implemento, limitador de altura, limitador de curso, entre outros.

Tabela 2 - Coordenadas dos controles do trator New Holland 7630.

\begin{tabular}{l|c|c|cc}
\hline$\downarrow$ Controles & Coordenadas $\rightarrow$ & $\mathbf{X}$ & $\mathbf{Y}$ & $\mathbf{Z}$ \\
\hline Ponto de fixação 1 & 0 & 0 & 0 \\
Ponto de fixação 2 & 0 & 0 & 0 \\
Ponto de fixação 3 & 0 & 0 & 0 \\
Ponto de fixação 4 & 0 & 0 & 0 \\
Interruptor da partida & -120 & 580 & -98 \\
Tração & 93 & 682 & 15 \\
Redução de marcha & -128 & 682 & 15 \\
Tomada de força & -250 & 123 & -295
\end{tabular}


Conformidade ergonômica dos controles no posto de trabalho ... : Estudo de Caso Nh 7630

\begin{tabular}{|c|c|c|c|c|}
\hline$\downarrow$ Controles & Coordenadas $\rightarrow$ & $\mathrm{x}$ & $\mathbf{Y}$ & $\mathbf{z}$ \\
\hline \multicolumn{2}{|c|}{ Controle remoto 1} & 413 & 23 & -100 \\
\hline \multicolumn{2}{|c|}{ Controle remoto 2} & 360 & 23 & -120 \\
\hline \multicolumn{2}{|c|}{ Controle de levantar e abaixar implementos - } & 328 & 100 & -185 \\
\hline \multicolumn{2}{|c|}{ Controle de levantar e abaixar implementos - } & 330 & 303 & -370 \\
\hline \multicolumn{2}{|c|}{ Limitador de altura } & 328 & 100 & -325 \\
\hline \multicolumn{2}{|c|}{ Limitador de curso } & 328 & 100 & -325 \\
\hline \multicolumn{2}{|c|}{ Seletor de sensibilidade } & 278 & 75 & -250 \\
\hline \multicolumn{2}{|c|}{ Bloqueio do diferencial } & 273 & 252 & -503 \\
\hline \multicolumn{2}{|c|}{ Acelerador manual - baixa } & 185 & 542 & 65 \\
\hline \multicolumn{2}{|c|}{ Acelerador manual - alta } & 185 & 655 & 125 \\
\hline \multicolumn{2}{|c|}{ Acelerador de pé - alta } & 406 & 540 & -522 \\
\hline \multicolumn{2}{|c|}{ Acelerador de pé - baixa } & 435 & 515 & -498 \\
\hline \multicolumn{2}{|c|}{ Freio de pé - direito } & 335 & 680 & -457 \\
\hline \multicolumn{2}{|c|}{ Freio de pé - esquerdo } & 235 & 680 & -457 \\
\hline \multicolumn{2}{|c|}{ Embreagem } & -254 & 565 & -380 \\
\hline \multicolumn{2}{|c|}{ Freio de estacionamento } & 112 & 482 & -348 \\
\hline \multicolumn{2}{|c|}{ Alavanca de mudança câmbio - neutro } & 0 & 380 & -58 \\
\hline \multicolumn{2}{|c|}{ Alavanca de mudança câmbio - 1} & -60 & 442 & -43 \\
\hline \multicolumn{2}{|c|}{ Alavanca de mudança câmbio - 2} & 0 & 442 & -43 \\
\hline \multicolumn{2}{|c|}{ Alavanca de mudança câmbio - 3} & -60 & 325 & -98 \\
\hline \multicolumn{2}{|c|}{ Alavanca de mudança câmbio - 4} & 10 & 442 & -43 \\
\hline \multicolumn{2}{|c|}{ Alavanca de mudança câmbio - $R$} & 0 & 330 & -88 \\
\hline \multicolumn{2}{|c|}{ Alavanca alta e baixa/grupos - neutro } & 130 & 443 & -120 \\
\hline \multicolumn{2}{|c|}{ Alavanca alta e baixa/grupos - A } & 123 & 388 & -138 \\
\hline \multicolumn{2}{|c|}{ Alavanca alta e baixa/grupos - B } & 135 & 488 & -110 \\
\hline \multicolumn{2}{|c|}{ Luzes/Farol - Liga/alta/baixa } & 125 & 573 & -166 \\
\hline \multicolumn{2}{|c|}{ Volante } & 0 & 503 & 157 \\
\hline \multicolumn{2}{|c|}{ Botão de alerta } & 127 & 682 & 15 \\
\hline \multicolumn{2}{|c|}{ Alavanca de seta } & -78 & 575 & 17 \\
\hline \multicolumn{2}{|l|}{ Buzina } & 125 & 573 & -104 \\
\hline
\end{tabular}

Fonte: Autoria própria.

O modelo New Holland 7630, os pontos de fixação são encobertos pelo suporte do banco do trator, com isto não podem ser coletadas as coordenadas necessárias do ponto de fixação.

Para a verificação da conformidade posicionamento dos controles em relação a norma NBR ISO 6682, foi convertido as medidas estibuladas na norma e inseridas as coordenadas tridimensionais no software Rhinoceros 3.0. Posteriormente o posicionamento tridimensional dos controles foram inseridos sob a plataforma virtual, conforme demonstrado nas Figuras 11,12 e 13. 


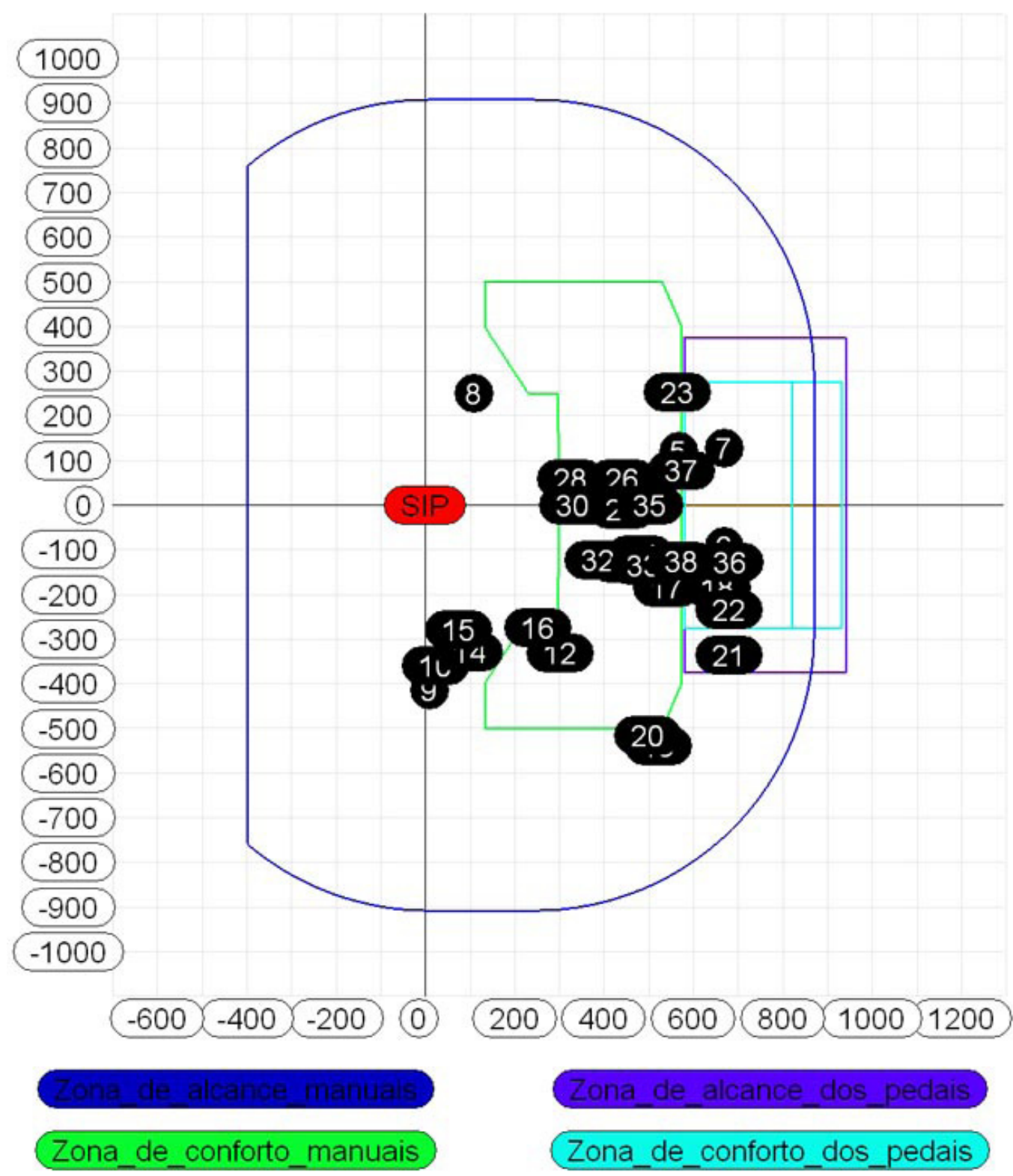

Figura 11 - Zonas de conforto e alcance - Vista Superior Fonte: Autoria própria.

Na Figura 11 demonstra que todos os controles estão inseridos dentro da zona de alcance, mas podemos destacar como controles principais relativo ao trator, os únicos que estão dentro da zona de conforto são:

- 35 - Volante,

- 25 a 30 - Alavancas de mudança de câmbio,

- 31 a 33 Alavancas de grupos,

- 21 e 22 - Freio de pé,

- 17 e 18 - Acelerador manual,

Os controles que estão fora da zona de conforto, como o número 23 - Embreagem, e os números 19 e 20 - Acelerador de pé, são de uso freqüente para o operador, sendo eles necessários dentro da zona de conforto. 


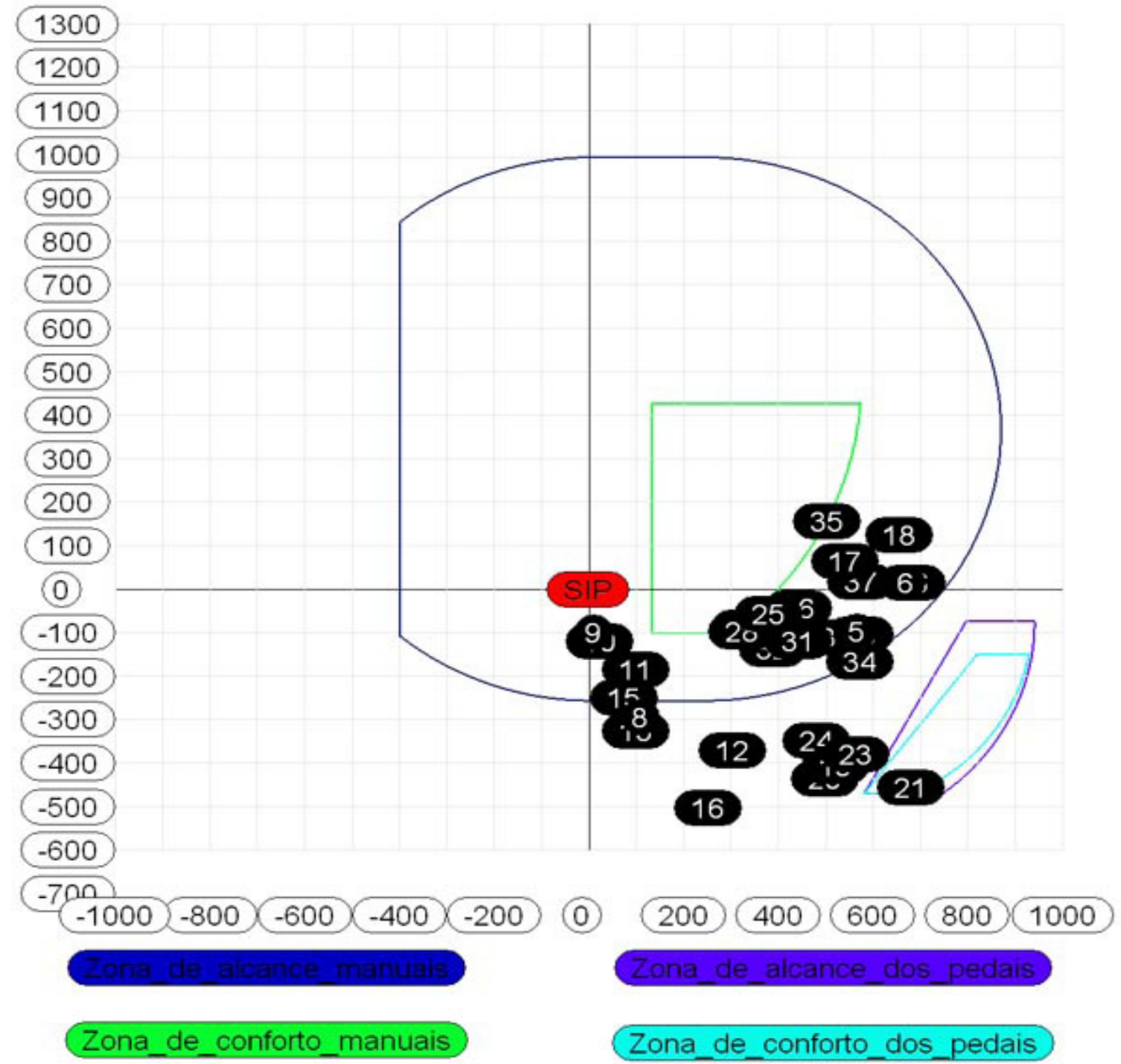

Figura 12 - Zonas de conforto e alcance - Vista Lateral

Fonte: Autoria própria.

A visualização lateral demonstrada na Figura 12, é exposto os seguintes controles fora da zona de alcance, são:

- 8 - Tomada de força,

- 12 - Controle de levantar e abaixar implementos - baixado,

- 13 - Limitador de altura,

- 16 - Bloqueio do diferencial,

- 19 - Acelerador de pé - alta,

- 20 - Acelerador de pé - baixa,

- 23 - Embreagem,

- 24 - Freio de estacionamento.

Dentre os controles fora da zona de alcance, podemos destacar o acelerador de pé e a embreagem, controles primários dos membros inferiores, sendo que os mesmos deveriam estar dentro da zona de conforto do operador. 


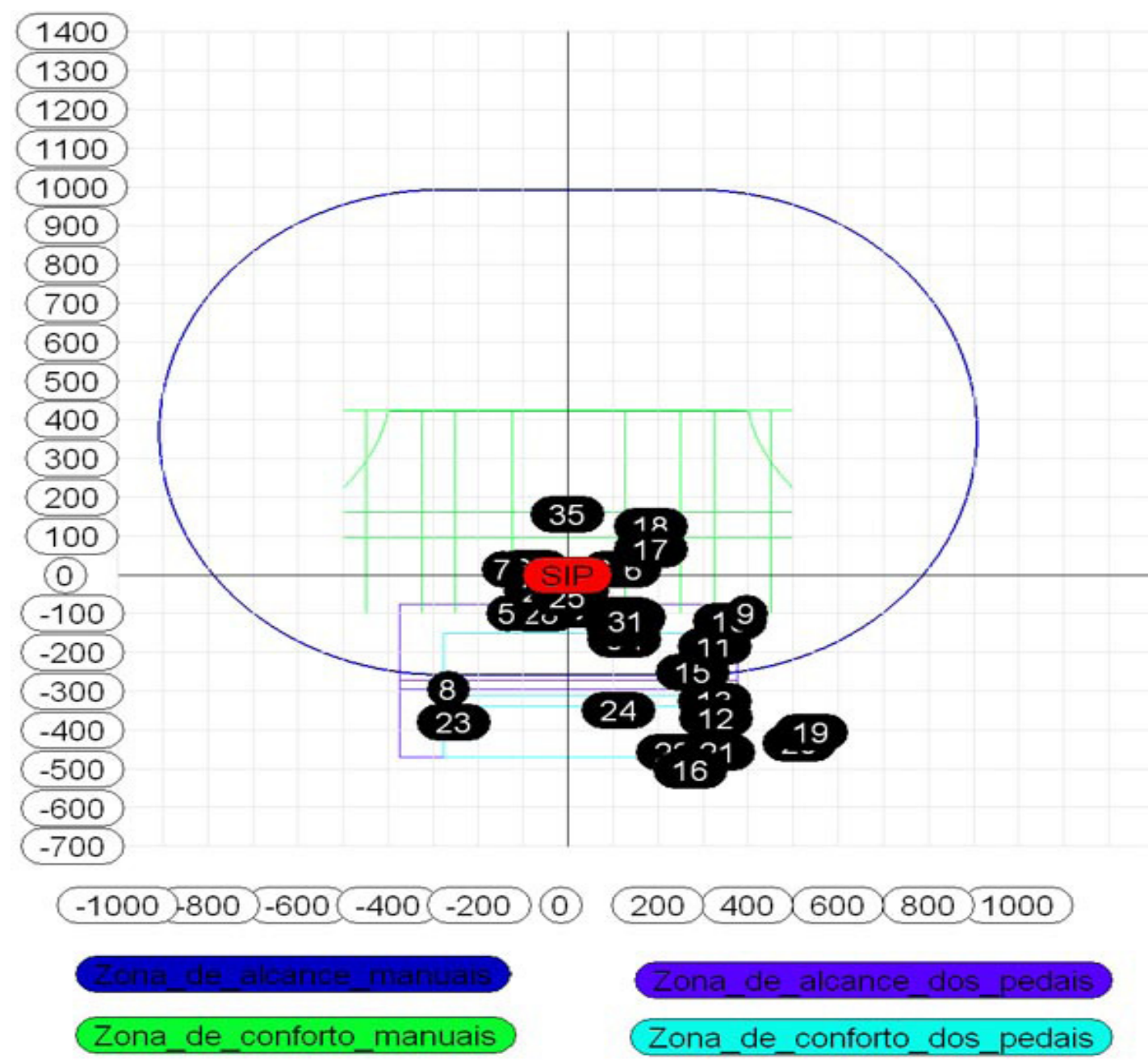

Figura 13 - Zonas de conforto e alcance - Vista Frontal Fonte: Autoria própria.

A Figura 13, expõe os seguintes controles fora da zona de alcance, demonstrados a seguir:

- 8 - Tomada de força,

- 12 - Controle de levantar e abaixar implementos - baixado,

- 13 - Limitador de altura,

- 16 - Bloqueio do diferencial,

- 19 - Acelerador de pé - alta,

- 20 - Acelerador de pé - baixa,

- 23 - Embreagem,

- 24 - Freio de estacionamento.

Os controles de acelerador de pé e embreagem, estão posicionados fora da zona de conforto, tendo uma abdução considerável do membro inferior do operador, podendo ocasionar lesões musculoesquelética em usos freqüentes.

Tabela 3 - Controles dispostos nas zonas de alcance e zonas de conforto, segundo a NBR ISO 6682 - Máquinas rodoviárias - Zonas de conforto e alcance dos controles.

Conforme demonstrado na Tabela 3, tendo como base a norma NBR ISO 6682 (2004) -

Projética Revista Científica de Design I Universidade Estadual de Londrina I V.2 I N.1 I Junho 2011 
Conformidade ergonômica dos controles no posto de trabalho ... : Estudo de Caso Nh 7630 Máquinas rodoviárias - Zonas de conforto e alcance dos controles, dos trinta e oito controles analisados, dezessete controles são de uso primário, e somente três controles estão em conformidade com a norma. Os controles primários que estão em conformidade com a NBR ISO 6682 são: 21 - Freio de pé - direito; 22 - Freio de pé - esquerdo e o 35 - Volante.

\section{Conclusão}

Esta pesquisa enfatiza mais os conceitos descritos por Russo, llgner e Buzatto (1998), de que os equipamentos e implementos agrícolas não possuem parâmetros antropométricos necessários para o operador de trator brasileiro, tendo seus projetos mal elaborados e dimensionamentos incorretos do invólucro do posto de trabalho para o acionamento de determinados controles.

A realização de um projeto de trator agrícola em outros países, vai de desencontro da real necessidade ergonômica do consumidor brasileiro, a qual abrange uma grande miscigenação de etnias entre trabalhadores de todas as regiões.

O uso da tecnologia em proveito desta atividade pode promover melhorias nos postos de trabalho, substituindo alavancas por botões, inserindo mais comandos em um pequeno espaço, e com isso oferecendo um maior conforto ao operador.

Assim, conclui que, a partir dos problemas inicialmente levantados e da avaliação do posto de trabalho do operador de trator, os controles não estão e conformidade com a norma NBR/ISO 6682 (2004) - Máquinas rodoviárias - Zonas de conforto e alcance dos controles.

Nota-se a necessidade em se recordar que o princípio da ergonomia é que o trabalho tem que estar adequado ao homem, e não o homem ao trabalho.

\section{Referências}

ASSOCIAÇÃO BRASILEIRA DE NORMAS TÉCNICAS. NBR/NM/ISO 5353: máquinas rodoviárias e tratores e máquinas agrícolas e florestais: ponto de referência do assento. Rio de Janeiro, mar. 1999.

. NBR/ISO 4130: veículos rodoviários automotores: sistema de referência tridimensional e marcas de referência: definições. Rio de Janeiro, nov. 2007.

.NBR/ISO 6682: máquinas rodoviárias: zonas de conforto e alcance dos controles. Rio de Janeiro, set. 2004.

DUL, J.; WEERDMEESTER, B. Ergonomia prática. 2. ed. São Paulo: Blücher, 2004.

GOMES, C. Z.; SANTOS, J. E. G.; FERNANDES, João C. Usuário $x$ a interface tecnológica dos produtos agrícolas: fatores socioculturais e ambientais que interferem na atividade. In: CONGRESSO INTERNACIONAL DE PESQUISA EM DESIGN, 3., 2005, Rio de Janeiro. Anais... Rio de Janeiro: ESDI, 2005. CD-ROM.

GRANDJEAN, E. Manual de ergonomia: adaptando o trabalho ao homem. 4. ed. Porto Alegre: Bookman, 1998.

IIDA, I. Ergonomia: projeto e produção. 2. ed. São Paulo: Blücher, 2005. 
Marcos Antonio Rossi; João Eduardo Guarnetti dos Santos; André Luis da Silva

LAVILLE, A. Ergonomia. São Paulo: Ed. da Universidade de São Paulo, 1977.

MÁRQUEZ, L. Maquinaria agrícola y seguridad vial. Boletim Salud y Trabajo, Madrid, n. 56, p. 6, 1986.

MONTEDO, U. B. O trabalho na unidade de produção agrícola familiar segundo a teoria da complexidade. 2001. Tese (Doutorado em Engenharia de Produção) - Universidade Federal de Santa Catarina, Florianópolis.

MORAES, A.; MONT'ALVÃO, C. Ergonomia: conceitos e aplicações. 2. ed. Rio de Janeiro: 2AB, 2000.

MURREL, K.F. H. Ergonomics: man and his working environment. London: Chapman and Hall, 1965.

VIDAL, M. C. Introdução à ergonomia. Rio de Janeiro. 2009. Disponível em: <http://www.gente. ufrj.br/ceserg/arquivos/erg001.pdf>. Acesso em: 3 abr. 2004.

PANERO, J.; ZELNIK, M. Dimensionamento humano para espaços interiores. Barcelona: Gustavo Gili, 2002.

PHEASANT, S. T.; HARRIS, C. M. Human strength in the operation of tractor pedals. Ergonomics, London, v. 25, n. 1, p. 53-63, 1982.

ROZIN, D. Conformidade do posto de operação de tratores agrícolas nacionais com normas de ergonomia e segurança. 2004. Dissertação (Mestrado em Engenharia Agrícola) - Universidade Federal de Santa Maria, Santa Maria.

RUSSO, S.; ILGNER, N.; BUZATTO, M. Verificação dimensional de máquinas agrícolas com relação ao perfil antropométrico do agricultor na área de abrangência de Santo Ângelo. 1998. Disponível em: <http://www.urisan.tche.br/ gep/1998/verificacaodimensional.pdf>. Acesso em: 5 jul. 2004.

SANTOS, N.; DUTRA, A. R. A.; FIALHO, F. A. P.; PROENÇA, R. P. C.; RIGHI, C. R. Antropotecnologia: a ergonomia dos sistemas de produção. Curitiba: Gênesis, 1997.

SCHLOSSER, J. F.; DEBIASI, H.; PARCIANELLO, G.; RAMBO, L. Caracterização dos acidentes com tratores agrícolas. Ciência Rural, Santa Maria, v. 32, n. 6, p. 977-981, 2002. 